\title{
Composite Contracts in Supply Chain
}

\author{
TAMÁS FALUDI \\ PHD STUDENT \\ UNIVERSITY OF MISKOLC \\ e-mail: szvft@uni-miskolc.hu
}

\begin{abstract}
SUMMARY
Supply chain coordination is very important nowadays because of the increasing number of cooperating partners. Contracts can be used in order to provide a framework for the partners' cooperation. In this paper, two contract types are analysed. Take-it-or-leave-it contracts are often used by decentralized supply chains, but include some attributes from centralized settings. The quantity discount can be used in any type of supply chain. Centralized and decentralized settings of supply chains are also discussed in the paper. A numerical example compares the rates which determine the coordination power of the contract types. The paper suggest some other composite contracts to enhance the performance of supply chains.
\end{abstract}

Keywords: Supply Chain Management, Supply Chain Coordination, Contract Types, Quantity discount, Take-it-or-leaveit

Journal of Economic Literature (JEL) codes: D21, L11, L14, M10

DOI: http://dx.doi.org/10.18096/TMP.2020.01.01

\section{INTRODUCTION}

Contracts are one of the most popular forms for coordinating supply chains. As a hard tool, contracts give a framework for the cooperation, determining the conditions of risk and benefits-sharing in the case of uncertainty in either the supply or the demand (Coltman et al. 2009). Therefore, the contract minimizes the number of the possible conflicts, bringing balance in the chain, and this can decrease the level of different dominances.

Nowadays a number of researchers deal with contracts - for example they analyse the coordination power of the different types, creating numerical examples to determine the advantages and disadvantages of use. There are different types of traditional contracts and some authors try to mix these contracts to create some hybrid or extremely complex types, because these solutions can be relevant to the coordination issue (Katok \& Pavlov 2013; Zhang et al. 2013; Molnár 2017).

This paper introduces one non-traditional composite contract and one traditional; the take-it-or-leave-it contract and the quantity discount contract. Take-it-or-leave-it contracts use the advantages of a centralized setting, which is the preferred setting for supply chains. Both types can be used in decentralized supply chains. The aim of this paper is to determine which type is better in terms of supply chain coordination.

\section{Possible SeTtings OF THE SUPPLY CHAIN}

There is a significant question in terms of coordination - the setting. It is important what kind of setting is used by the chain. Two possible settings are identified; a decentralized setting is preferred by companies, because they can act in their own interest, but according to the studies of many researchers, a centralized setting can be better (e.g. Chakraborty et al. 2015).

\section{Decentralized Setting of the Supply Chain}

This is the classical approach. The level of cooperation between the partners is minimal, they do not share all information - for example about the demand - with each other, and the chain members are interested in maximizing their own profit. The decentralized setting exists because the companies deal with their short-term goals. But this approach is not profitable for the supply chain members in the long term.

The members can maximize their profit, but only in the short term. This process is at the expense of the others' performance. These companies will decrease the quantity of the orders, therefore the profits of all members will also decline. Consequently, the total profit will decrease.

We can realize the biggest problem of the decentralized setting if we analyse the behaviour of two side-by-side 
chain members. The goal of the customer is to purchase the largest quantity at the lowest available price. But the second member would like to sell its products at the highest price possible, because of profit maximization. Thus, the chain members have conflicts of interest. In the beginning, member one can maximize its profit, but later, because of the higher prices, member two is going to reduce the needed quantity from order to order, and in the worst case it will search for another partner. Neither of the members can maximize the profit, thus the total profit of the whole chain will not be satisfactory. This phenomenon leads to double marginalization (Li et al. 2013). This is the major disadvantage of the decentralized setting.

\section{The Vertical Integration of Supply Chain}

Coordination mechanisms try to eliminate the negative effects of double marginalization. For this, it is necessary to enhance the cooperation and the level of informationsharing (Giannocaro 2018). The first and the most important step for the chain members is to strive for longterm cooperation instead of short-term profit maximization. It helps to increase the level of vertical integration, which means the totally cooperation between the members. Actually, the vertical integration of supply chain means the centralized setting.

This kind of centralized setting is difficult to implement, but it leads to more efficient operation than the decentralized setting. The members prioritize the goals of the whole supply chain and they operate in a way that will reach these goals. The level of information-sharing and cooperation is higher than in the decentralized setting.

Usually, this setting has a leader - called the 'supply chain leader' - who is a relatively dominant member in the chain. The leader makes the strategic decisions to maximize the total profit and increase the efficiency of the supply chain (Pibernik \& Sucky 2006). Because of this leader, this setting is called centralized.

The operation of the centralized setting assumes longterm planning. The chain members do not focus on maximizing their own profit in a short-term period, because they can realize a higher profit in the long term.

The prices in the case of the centralized setting are lower, which stimulates the quantity sold. The higher the quantity sold, the higher the realizable profit. So this means that the total profit of the chain can be also higher. In the case of a decentralized setting, members want to maximize just their own profit, meaning higher prices. As a result the quantity sold is lower and this undermines the overall profitability - and of course the performance - of the decentralized supply chain (Simchi-Levi et al. 2003).

According to the literature, centralized supply chains are preferred, because with vertical integration the cooperation of chain members can be improved, which is one of the major prerequisites for supply chain coordination.

\section{CONTRACTS}

Contracts are a rewarding area for researchers because they are a method to help in the coordination of supply chains. To make coordination better and more successful we can use soft tools and hard tools (Szegedi 2017). Coordination with the help of the different types of contracts belongs to the group of hard tools, which controls the transactions, the production volumes and manages the financial actions for the economic operation.

Contracts try to form relative equality between chain members because a framework is provided for the cooperation. It is determined how partners are to share risks and benefits (Coltman et al. 2009). According to the research of Wang et al. (2013), contracts are used to enhance the performance of the whole supply chain.

Cachon (2003) determines the requirements that have to be fulfilled by contracts to be successful in the long term. First is feasibility: the conditions must be reasonable, otherwise contracts will put all of the partners at a disadvantage. Contracts need to be flexible to adapt to the dynamically changing environment and also to the needs of the parties signing the agreement. A contract can be successful if it satisfies the needs of both parties, especially in terms of making profit. There will be maximum satisfaction when this process is fair. Thus, the most important task of the contract is to reduce the inequity caused by a difference in the dominance level of the chain members. With this the profit can be divided more equally and fairly between the members.

There are many types of contracts to help coordination. Traditional types are relatively simple, while a composite contract has more complicated conditions. The hybrid ones use at least two contracts to mix their parameters (Arani et al. 2016).

Here one example of each type of contract will be presented. The paper also includes a numerical example to analyse the coordination level of concrete contracts.

\section{Take-it-or-Leave-it Contracts}

The name derives from the essence of the contract: first step, supplier offers the price, second step, customer accepts or refuses this offer. If the price is accepted, the customer can take the ordered items for the same price during the pre-agreed interval. If the price is not accepted, the customer leaves the items and the agreement is not concluded (Polo \& Scarpa 2013). This could be risky for the customer, because a new offer from a different partner may include a higher price.

Because of the fixed prices and the fixed payment, the supplier is protected against non-payment. The customer will receive the ordered quantity, because in the case of the take-it-or-leave-it contract, there is a delivery threshold, which is determined by the customer. This assumes that the customer will define a high enough threshold to satisfy its needs in any case. The customer orders this quantity and 
pays for it, but there is no need to deliver the entire shipment at the same time. The conditions allow the customer to control the quantity of each delivery in the preagreed period. This means that the customer can increase or decrease the actual quantity of certain orders up to the threshold. Therefore, the customer is also protected against non-delivery (Polo \& Scarpa 2013).

\section{Quantity Discount Contracts}

This is probably one of the most popular contract types. The contract can be used in both centralized and decentralized settings. The unit price depends on the ordered quantity. This means that if the retailer increases the quantity ordered, the supplier can give a lower unit price. Thus the retailer is motivated to buy higher quantities. If the demand is uncertain, the customer can overstock, while the supplier may run out of stock. This is definitely a disadvantage of the quantity discount.
To avoid this problem, some research tries to find an optimal quantity of order. If the quantity sold is the same as in the centralized setting, the best performance is available. Any other option of the discount results in worse rates (Molnár \& Faludi 2019). So the quantity discount can coordinate the supply chain, if members use the optimal quantity.

\section{COMPARISON WITH NUMERICAL EXAMPLE}

I would like to present the coordination power of the contracts analysed before. To measure the efficiency, I compare the total profits, the individual profits, the unit prices and the market prices. The symbols of analysed rates, the notations and the available economic parameters are shown in Table 1.

Table 1

Notations and economic parameters

\begin{tabular}{|c|c|c|}
\hline Constant (1) & $\mathrm{V}$ & 115 \\
\hline Constant (2) & $\mathrm{W}$ & 1.8 \\
\hline Market price & $\mathrm{P}_{\mathrm{MD}}$ & $115-1.8 * \mathrm{OQ}$ \\
\hline Revenue-sharing rate of Member \#1 (Supplier) & $\mathrm{M}_{1} \alpha$ & 0.6 \\
\hline Revenue-sharing rate of Member \#2 (Retailer) & $\mathrm{M}_{2} \alpha$ & 0.4 \\
\hline Cost of Member \#1 (Supplier) & $\mathrm{M}_{1} \mathrm{C}$ & 28 EUR \\
\hline Cost of Member \#2 (Retailer) & $\mathrm{M}_{2} \mathrm{C}$ & 13 EUR \\
\hline Total cost of the members & $\sum \mathrm{MC}$ & $41 \mathrm{EUR}$ \\
\hline Unit price & UP & depends on the contract type \\
\hline Ordered quantity & OQ & depends on the contract type \\
\hline Individual profit (Member \#1 - Supplier) & $\mathrm{M}_{1} \Pi$ & depends on the contract type \\
\hline Individual profit (Member \#2 - Retailer) & $\mathrm{M}_{2} \Pi$ & depends on the contract type \\
\hline Total profit & $\sum \mathrm{M \Pi}$ & depends on the contract type \\
\hline
\end{tabular}

Source: own construction 


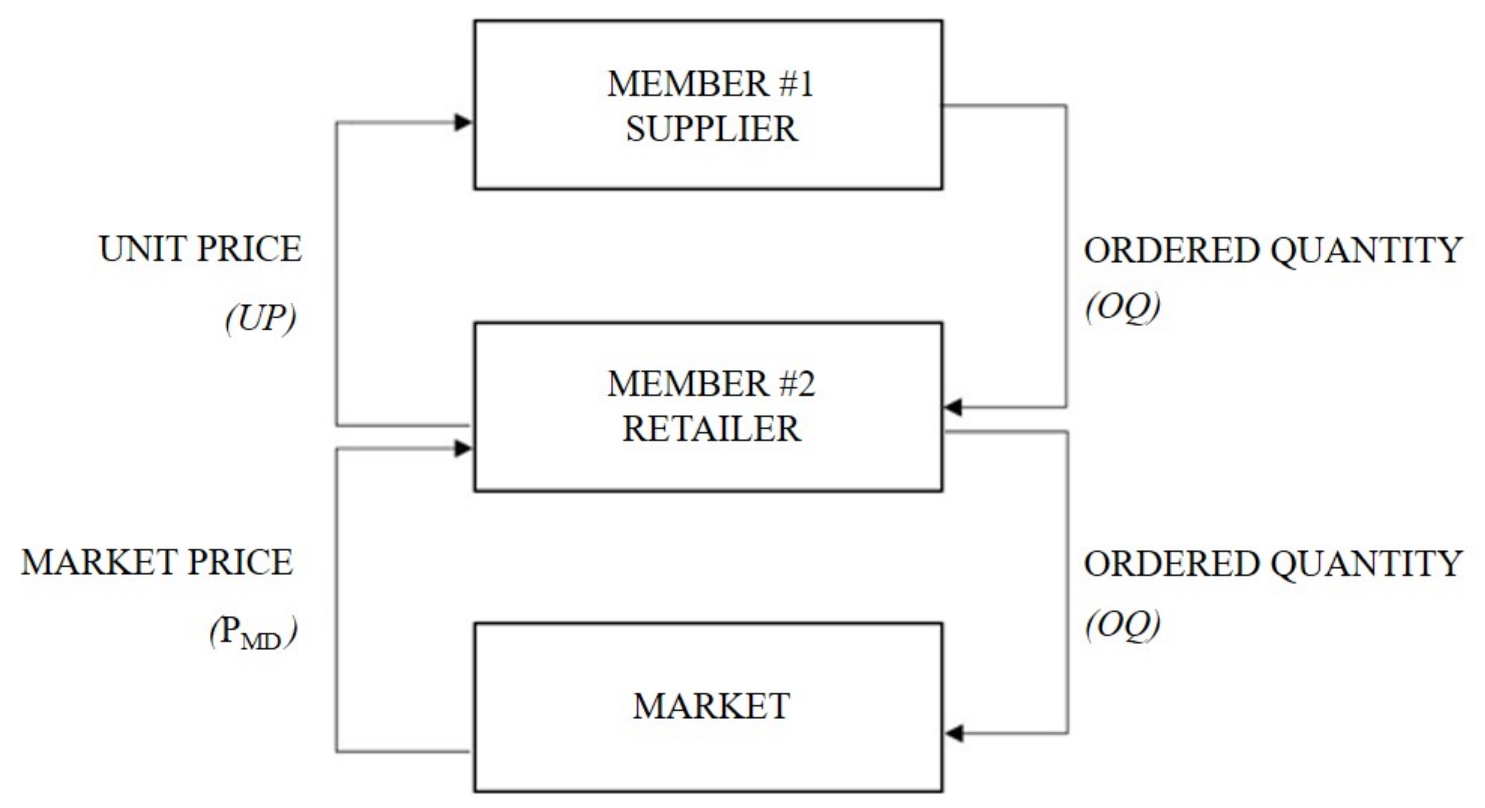

Source: own construction

Figure 1. The structure of model

The market price $\left(\mathrm{P}_{\mathrm{MD}}\right)$ is determined by the simplified market demand function. This function includes the retailer's ordered quantity (it is the real market demand), and $\mathrm{v}$ and $\mathrm{w}$, the market constants. The model assumes that all members are aware of this information and all of the chain members know that the other members are aware of this knowledge.

Some calculations are the same in the case of every contract type. However, the unit price, the individual profits and the total profit have different calculations, and these depend on the contract type. The revenue-sharing rate must be determined because it is needed to calculate some rates of the quantity discount contract. A simple supply chain with two members is used here (Figure 1).

The take-it-or-leave-it contract type mixes the characteristics of the centralized and decentralized settings. The calculation of the ordered quantity belongs to the centralized setting, so with this quantity the total profit can be maximized. But the unit price maximizes the individual profit for the supplier, which is typical of decentralized supply chains.

The reason for this is found in its extreme nature. The ordered quantity is determined with the help of the total profit function of centralized setting. The total profit of the supply chain (Equation (1)) is maximized on the basis of the market demand, which will be the partial derivative of the quantity. If the equation is equal to zero, the ordered quantity can be expressed (Equation (2)).

$$
\begin{aligned}
& \sum \Pi=\left(v-w \cdot O Q-\sum M C\right) \cdot O Q \\
& \frac{\partial \sum \Pi}{\partial O Q}=0 \rightarrow O Q=\frac{v-\sum M C}{2 \cdot w}
\end{aligned}
$$

To determine the unit price, it is needed to use the profit function of the supplier (Equations (3)-(4)). Because the profit maximization is on the basis of the unit price, using the decentralized setting calculation for the ordered quantity is necessary (Equation (3)).

The supplier's profit depends on his cost and the unit price that he gets from the retailer, each of which is influenced by the ordered quantity. In the case of the retailer, calculations start with the market price paid by the customer, this is the income. This value will be decreased by the unit price paid to the supplier, and the retailer's own costs - of course the ordered quantity will influence the profit. The calculations are given in Equations (3) and (5). 


$$
\begin{aligned}
& M_{1} \Pi=\left(U P-M_{1} C\right) \cdot O Q=\left(U P-M_{1} C\right) \cdot \frac{v-U P-M_{2} C}{2 \cdot w} \\
& \frac{\partial M_{1} \Pi}{\partial U P}=0 \rightarrow U P=\frac{v-M_{2} C+M_{1} C}{2} \\
& M_{2} \Pi=\left(P_{M D}-U P-M_{2} C\right) \cdot O Q \\
& M_{1} \Pi=\frac{\left(1-M_{2} \alpha\right) \cdot\left(P_{M D} \cdot O Q\right)}{O Q}+M_{2} \alpha \cdot \sum M C . \\
& M_{2} \Pi=\left(P_{M D} \cdot O Q\right)-(U P \cdot O Q)
\end{aligned}
$$

While the take-it-or-leave-it type allows the customer or retailer to refuse the contract, the quantity discount type does not allow this. But a quantity discount offers more flexible conditions than the take-it-or-leave-it contract.

According to the literature, the quantity discount performs at its best if the ordered quantity is the same as in the centralized supply chain (Molnár \& Faludi 2019). For this reason, I analyse this case to test whether this is indeed true. To determine this value, Equation (2) must be used, which means that the ordered quantity will be the same in both contracts.

The supplier's profit is the total profit and the righthand portion of the revenue-sharing rate Equation (6)).

At this point, we must take into account the connection between the quantity discount type and the revenuesharing contract. A revenue-sharing contract allows us to divide the retailer's profit among the chain members by the predetermined revenue-sharing rate. In case of the quantity-discount type, this rate appears only in the supplier's profit, while the retailer does not gain any extra profit from the revenue-sharing.

The profit of the retailer is influenced by the prices (Equation (7)).

The results of the calculation are included in the next section.

\section{RESULTS AND RECOMMENDATIONS}

The results of applying the formulas and the data in the previous chapter are shown in Table 2.

Table 2

Results of the calculation

\begin{tabular}{|c|c|c|c|c|c|c|}
\hline & $\boldsymbol{O Q}$ & $\boldsymbol{P}_{\boldsymbol{M D}}$ & $\boldsymbol{U P}$ & $\boldsymbol{M}_{\mathbf{1}} \boldsymbol{\Pi}$ & $\boldsymbol{M}_{\mathbf{2}} \boldsymbol{\Pi}$ & $\sum \boldsymbol{M} \boldsymbol{\Pi}$ \\
& $100 \mathrm{pcS}$ & EUR & EUR & 100 EUR & 100 EUR & 100 EUR \\
\hline $\begin{array}{c}\text { Take-it-or- } \\
\text { leave-it }\end{array}$ & 20.56 & 78 & 65 & 760.72 & 0 & 760.72 \\
\hline $\begin{array}{c}\text { Quantity } \\
\text { discount }\end{array}$ & 20.56 & 78 & 63.2 & 456.33 & 304.288 & 760.62 \\
\hline
\end{tabular}

Source: own construction 
The results of the two types are very similar. The market price is the same, and because the contracts partly use the centralized settings, the ordered quantities are equal in both cases. The total profit of the whole chain is almost equal - because the quantity discount offers somewhat lower prices, the total profit can be slightly lower in this case. But there is a very important difference between the analysed types: the profit-sharing mechanism.

As shown by the table, there is no profit for the retailer if the supply chain uses the take-it-or-leave-it contract. The total profit goes to the supplier. This creates inequality between the members, so using this type is recommended if the chain has very strong members with very strong bargaining power. The Supply Chain Management needs the members to implement the supply chain orientation which is based on cooperation, loyalty and trust - so the goal is to make a win-win situation. The results of take-itor-leave-it contract do not show that this type is the right choice for a supply chain. Not all kinds of supply chain can handle this contract, but the gas industry usually uses this type (Polo \& Scarpa 2013). For example take-it-or-leaveit contracts are used by Central and Eastern European gas suppliers MOL and Gazprom (Ostrowski \& Butler 2018). In this industry there are not very many suppliers but there are more customers. This means the customers have just a few choices to choose the right partner. In the case of the take-it-or-leave-it contract, the suppliers take advantage of this situation and that is the reason why this contract needs strong suppliers but weaker customers. Customers need the required volume of gas, so they are only interested in the quantity and not in profit. Suppliers, to maximize their profits, determine the unit price; their profit maximizing factor is the unit price. The take-it-or-leave-it contract allows these conditions. Therefore the take-it-or-leave-it contract is a good solution for both parties in the case of the gas industry.

The quantity discount contract shows fairer profit values. The supplier realizes higher profit than the retailer and this is realistic. However, a centralized setting is less typical than a decentralized setting. As a consequence, the ordered quantity shifts from the optimal level and this will decrease the performance of the chain member and the whole supply chain as well.

To enhance the performance of the supply chains, one potential solution can be a quantity flexible contract, which can be combined with a quantity discount (Chung et al.
2014). The simple quantity flexible contract first appeared at the end of the 1990s. Then - and unfortunately now as well - the proportion of supply chains in the decentralized setting was higher than centralized chains. This could be the reason why the quantity flexibility contract is often used by decentralized supply chains. The recommended type is a mix of the quantity discount and the take-it-orleave-it contract.

The higher the quantity the buyer orders, the greater the rate of discount that he gets if the quantity discount type is used. It is also good for the seller, who can realize better profit because of the higher quantity sold and can sell the accumulated inventory. But this is a disadvantage for the buyer; he overstocks because of the higher ordered quantity and it increases the costs and decreases the efficiency of his supply chain as well as of the whole supply chain.

One goal of the members, especially the one who is the closest to the market and thereby the customers, is to always have a sufficient supply to meet fluctuations in demand. Using a quantity flexibility contract avoids these problems. The contract allows the ordered quantity to be changed in real time, so the buyer can refresh his orders and can adapt to the demand in a better way. Similar to the take-it-or-leave-it type, there are limits for the ordered quantity. A maximum and minimum threshold need to be determined. Between these values the buyer can change the quantity ordered (Tsay 1999). Mainly, the contract allows both parties to share the risks and the costs - it protects against shortage and overstock (Heydari et al. 2019)

The take-it-or-leave-it type of contract is usually used by some decentralized supply chains - especially in the gas industry - but its applicability has limitations. The quantity discount contract is used in both decentralized and centralized settings. The optimal case is if the quantity sold is equal with the centralized setting; then the coordination power is the strongest (Molnár \& Faludi 2019). Actually, the quantity flexibility contract uses the positive attributes of the quantity discount and the take-it-or-leave-it types.

Further research directions can be to analyse the recommended contract types, such as the quantity flexibility contract or the revenue-sharing contract, since it has some features in common with the quantity discount contract. 


\section{Acknowledgement}

This research was supported by the project no. EFOP-3.6.2-16-2017-00007, titled "Aspects on the development of intelligent, sustainable and inclusive society: social, technological, innovation networks in employment and digital economy". The project has been supported by the European Union, co-financed by the European Social Fund and the budget of Hungary.

\section{REFERENCES}

ARANI, H.V., RABBANI, M., \& RAFIEI, H. (2016). A revenue-sharing option toward coordination of supply chains. International Journal of Production Economics, 178, 42-56. https://doi.org/10.1016/j.ijpe.2016.05.001

CACHON, G. P. (2003). Supply chain coordination with contracts. Handbooks in Operations Research and Management Science, Volume 11, pp. 227-339., https://doi.org/10.1016/s0927-0507(03)11006-7

CHAKRABORTY, T., SHAUHAN S. S., \& VIDYARTHI, N. (2015). Coordination and competition in a common retailer channel: Wholesale price versus revenue-sharing mechanisms. International Journal of Production Economics, No. 166, pp. 103-118., https://doi.org/10.1016/j.ijpe.2015.04.010

CHUNG, W., TALLURI, S., \& NARASIMHAN, R. (2014). Quantity Flexibility Contract in the Presence of Discount Incentive. Decision Sciences, Volume 45, Issue 1, pp. 49-79., https://doi.org/10.1111/deci.12058

COLTMAN, T., BRU, K., PERM-AJCHARIYAWONG, N., DEVINNEY, T. M., \& BENITO, G.G.R. (2009). Supply Chain Contract Evolution. European Management Journal, Volume 27, Issue 6, pp. 388-401., https://doi.org/10.1016/j.emj.2008.11.005

GIANNOCCARO, I. (2018). Centralized vs. decentralized supply chains: The importance of decision maker's cognitive ability and resistance to change. Industrial Marketing Management, Volume 73, August, pp. 59-69., https://doi.org/10.1016/j.indmarman.2018.01.034

HEYDARI, J., GOVINDAN, K., NASAB, H. R. E., \& TALEIZADEH, A. A. (2019). Coordination by quantity flexibility contract in a two-echelon chain system: Effect of outsourcing decisions. International Journal of Production Economics, 107586, https://doi.org/10.1016/j.ijpe.2019.107586

KATOK, E., \& PAVLOV, V. (2013). Fairness In Supply Chain contracts: A laboratory study. Journal of Operations Management, Volume 31, Issue 3, pp. 129-137., https://doi.org/10.1016/j.jom.2013.01.001

LI, X., LI, Y., \& CAI, X. (2013). Double marginalization and coordination in the supply chain with uncertain supply. European Journal of Operational Research 226, pp. 228-236., https://doi.org/10.1016/j.ejor.2012.10.047

MOLNÁR, V. (2017). Indirect Impacts of Drastic Scrap Rate Reduction on Costs of Production Process in Precision Machining. Solid State Phenomena 261, pp. 487-494., https://doi.org/10.4028/www.scientific.net/ssp.261.487

MOLNÁR, V., \& FALUDI, T. (2019). Comparison of supply-chain coordinating contract types. In: Nemec, Radek; Chytilova, Lucie (eds.) Proceedings of the 13th International Conference on Strategic Management and its Support by Information Systems 2019 : (SMSIS 2019)

Ostrava, Czech Republic: VSB-Technical University of Ostrava, pp. 60-67.

OSTROWSKI, W., \& BUTLER, E. (2018). Understanding Energy Security in Central and Eastern Europe: Russia, Transition and National Interest. Routledge Contemporary Russia and Eastern Europe Series, Routledge, New York, USA

PIBERNIK, R., \& SUCKY, E. (2006). Centralised and decentralised supply chain planning. International Journal of Integrated Supply Management, Vol. 2, Nos. 1-2, 2006, pp. 6-27., https://doi.org/10.1504/ijism.2006.008336

POLO, M., \& SCARPA, C. (2013). Liberalizing the gas industry: Take-or-pay contracts, retail competition and wholesale trade. International Journal of Industrial Organization 31, pp. 64-82., https://doi.org/10.1016/j.ijindorg.2012.10.003

SIMCHI-LEVI, D., KAMINSKY, P., \& SIMCHI-LEVI, E. (2008). Designing and Managing the Supply Chain: Concepts, Strategies and Case Studies. Boston: McGraw-Hill.

SZEGEDI, Z. (2017). Ellátásilánc-menedzsment (Supply Chain Management). Kossuth Kiadó, Budapest

TSAY, A. (1999). The quantity flexibility contract and supplier-customer incentives. Management Science, 45(10), pp. 1339-1358. https://doi.org/10.1287/mnsc.45.10.1339

WANG, X., WANG, X., \& SU, Y. (2013). Wholesale-price contract of supply chain with information gathering. Applied Mathematical Modelling, Vol. 37, Issue 6, 15 March, pp. 3848-3860. https://doi.org/10.1016/j.apm.2012.07.007

ZHANG, Q., DONG, M., LUO, J., \& SERGERSTEDT, A. (2013). Supply chain coordination with trade credit and quantity discount incorporating default risk. International Journal of Production Economics, Volume 153, pp. 352360., https://doi.org/10.1016/j.ijpe.2014.03.019 